
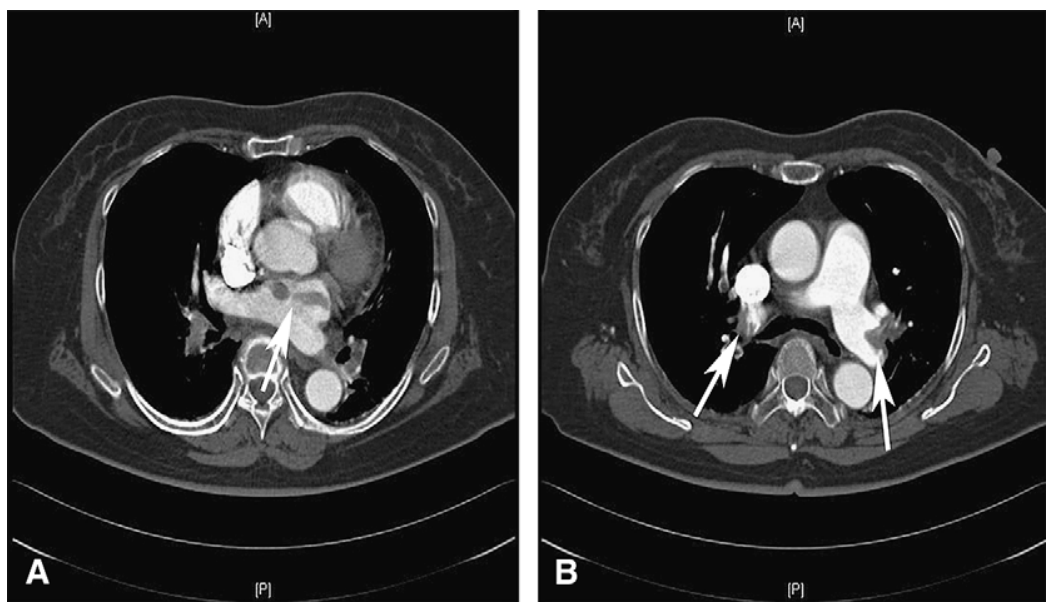

FIGURE 2. Computed tomography scan showing extension of embolus into the left atrium (A, arrow). Contrast-enhanced computed tomography scan showing the emboli (arrows) in the distal left and right main pulmonary arteries (B).

\title{
Lung transplantation for pulmonary alveolar microlithiasis
}

\author{
Norihisa Shigemura, MD, Christian Bermudez, MD, Brack G. Hattler, MD, Bruce Johnson, MD, \\ Maria Crespo, MD, Joseph Pilewski, MD, and Yoshiya Toyoda, MD, Pittsburgh, Pa
}

Since the first description of pulmonary alveolar microlithiasis (PAM) by Puhr ${ }^{1}$ in 1933, nearly 500 related cases have been reported worldwide. No effective treatment for PAM currently exists, with the exception of lung transplantation. Herein, we present the case of a 63-year-old woman with PAM who, to the best of our knowledge, is the oldest successful lung transplant recipient with end-stage PAM reported. In addition, the present work reviews the outcomes of other cases of PAM after lung transplantation.

\footnotetext{
From Cardiopulmonary Transplantation, University of Pittsburgh Medical Center, Pittsburgh, Pa.

Disclosures: None.

Received for publication May 27, 2008; accepted for publication July 5, 2008; available ahead of print Feb 23, 2009.

Address for reprints: Norihisa Shigemura, MD, Osaka University Graduate School of Medicine, Department of Thoracic Surgery, L5, 2-2 Yamada-oka, Suita, Suita, Osaka, 565-0871 Japan (E-mail: shigemura@thoracic.med.osaka-u.ac.jp).

J Thorac Cardiovasc Surg 2010;139:e50-2

$0022-5223 / \$ 36.00$

Copyright (c) 2010 by The American Association for Thoracic Surgery doi:10.1016/j.jtcvs.2008.07.066
}

\section{CLINICAL SUMMARY}

A 63-year-old woman with PAM was initially referred to our clinic for evaluation in 1998. The diagnosis was based on results of an open lung biopsy performed 16 years earlier, and the disease showed gradual progression, with 5 spontaneous instances of pneumothorax. The patient eventually became dependent on supplemental oxygen and was markedly limited in activities of daily living (from Fletcher Hugh-Jones criteria 4 to 5). She was deemed to be a suitable candidate for lung transplantation on the basis of our multidisciplinary transplant selection committee criteria. At the time of listing, she had moderately restricted pulmonary function with a forced vital capacity of $1.65 \mathrm{~L}$ (50\% of predicted), a forced expiratory volume in 1 second of $1.49 \mathrm{~L}(62 \%$ of predicted), and a diffuse capacity for carbon monoxide of $4.05 \mathrm{~L} \cdot \mathrm{min}^{-1} \cdot \mathrm{kPa}^{-1}(17 \%$ of predicted). Her 6-minute walk result was 830 feet on $5 \mathrm{~L}$ of oxygen provided via a nasal cannula with desaturation to $79 \%$. Cardiac catheterization showed a systolic pulmonary artery pressure of $47 \mathrm{~mm} \mathrm{Hg}$, a transpulmonary gradient of $22 \mathrm{~mm} \mathrm{Hg}$, and mild coronary artery disease. A chest radiograph and computed tomographic scan on admission are shown in Figure 1. 

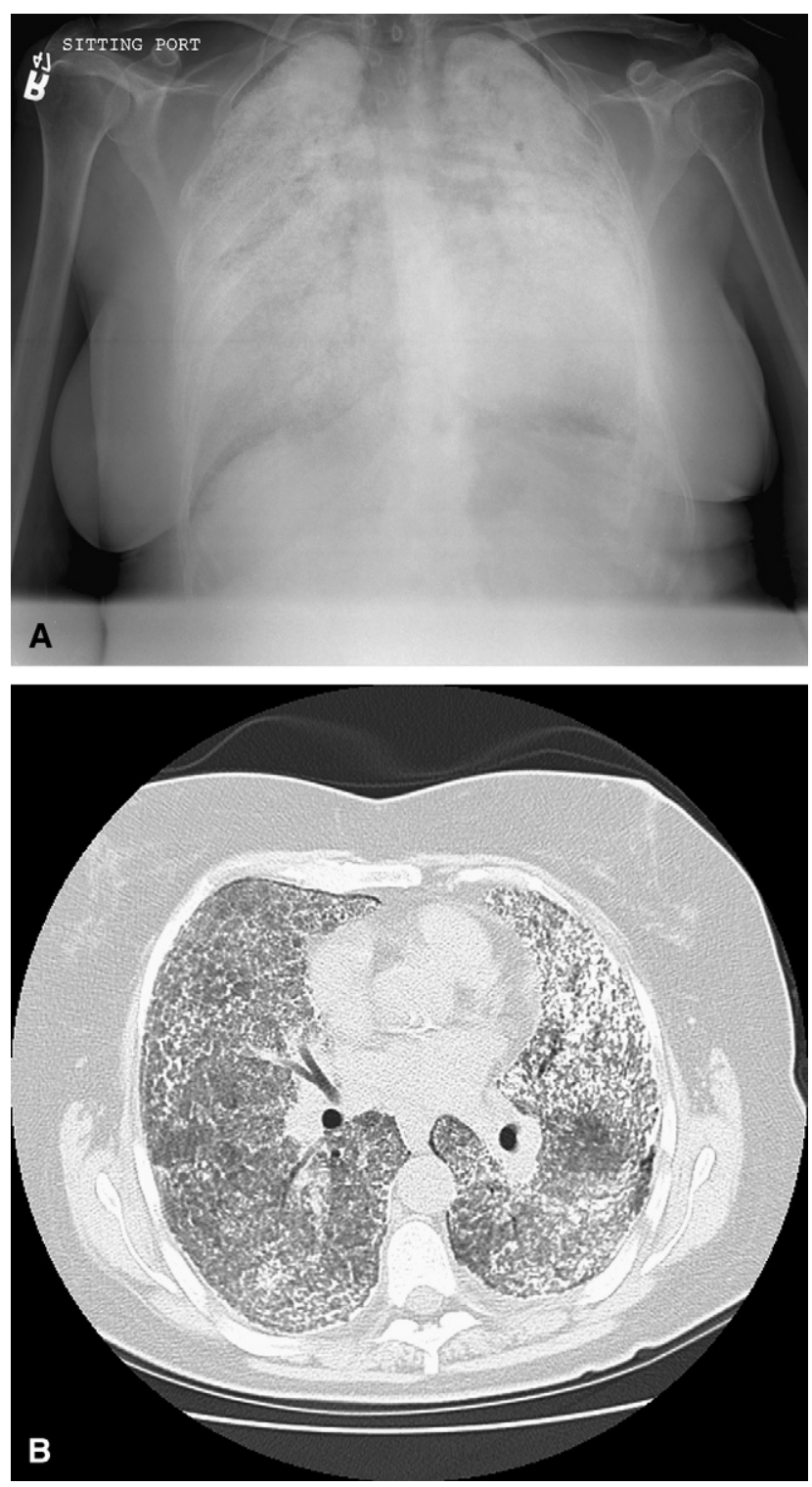

FIGURE 1. Chest radiograph (A) and computed tomographic scan (B) on admission.

In July 2006, a donor became available for our patient. The donor was a 52-year-old woman with a smoking history of 30 packs per year and a height of 66 inches, whereas the recipient was 67 inches in height. We performed double lung transplantation without cardiopulmonary bypass, during which severe adhesions were noted in the left side of the chest and moderate adhesions in the right. The apexes of the lungs were totally calcified and densely adherent to the chest wall bilaterally, which led to difficulties in removing the native lungs, although we were eventually successful. The allograft ischemic time was 256 minutes for the left and 392 minutes for the right. Immunosuppressive therapy consisted of intravenous alemtuzumab (Campath-1H) for

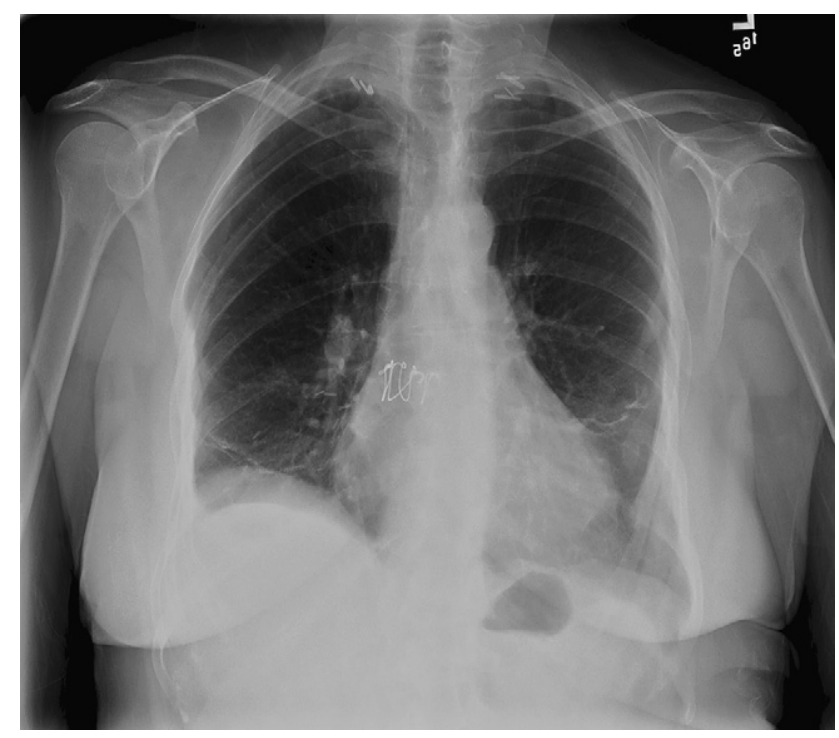

FIGURE 2. Chest radiograph 1 year after double lung transplantation.

induction, with oral tacrolimus (Prograf), mycophenolate mofetil (Cellcept), and prednisone given postoperatively. The patient had an uneventful postoperative recovery. She was extubated on postoperative day 1 and discharged from the hospital 21 days after transplantation, without supplemental oxygen. A chest radiograph 1 year after double lung transplantation is shown in Figure 2. At present, 2 years after transplantation, the patient leads an independent, active lifestyle and participates in normal activities of daily living without dyspnea or the need for supplemental oxygen. Her most recent pulmonary function test results showed a forced vital capacity of $2.25 \mathrm{~L}$ ( $70 \%$ of predicted) and a forced expiratory volume in 1 second of $1.84 \mathrm{~L}(81 \%$ of predicted).

\section{COMMENT}

We report a case of successful double lung transplantation in a 63-year-old patient with respiratory failure caused by PAM, a rare disease in which microliths are formed in alveolar air spaces. ${ }^{2}$ Although the disease progression is variable, the condition can remain static with minor clinical manifestations, despite striking radiographic features in affected individuals. Lung transplantation is the only effective treatment for PAM and has been described in several reports, ${ }^{3-6}$ which we have summarized in Table 1.

The timing of transplantation remains controversial. Edelman and associates ${ }^{5}$ suggested that it should be based on the functional status of the patient, given the indolent course of the disease. However, past reports related to PAM also noted that patients with a long history of the 
TABLE 1. Summary of past reports related to PAM after lung transplantation

\begin{tabular}{|c|c|c|c|c|c|c|c|c|c|}
\hline \multirow[b]{2}{*}{ Author (y) } & \multirow{2}{*}{$\begin{array}{l}\text { Patient } \\
\text { age }(y)\end{array}$} & \multicolumn{2}{|c|}{ Pretransplant } & \multicolumn{2}{|c|}{ After 1 y } & \multirow{2}{*}{$\begin{array}{c}\text { Double or single } \\
\text { transplant }\end{array}$} & \multirow[b]{2}{*}{ CPB } & \multirow[b]{2}{*}{ Complications } & \multirow[b]{2}{*}{ Outcome } \\
\hline & & $\operatorname{FVC~(L)~}$ & $\mathrm{FEV}_{1}(\mathrm{~L})$ & $\operatorname{FVC~(L)~}$ & $\operatorname{FEV}_{1}(\mathbf{L})$ & & & & \\
\hline 1. Bonnette (1992) & 46 & \multicolumn{4}{|c|}{ No data } & Double & Off & No & Alive \\
\hline 2. Stamatis (1993) & 32 & 2.3 & 1.8 & 3.6 & 2.7 & Double & On & Major bleeding & Alive, $18 \mathrm{mo}$ \\
\hline 3. Edelman (1997) & 56 & 1.11 & 0.99 & & & Double & On & Major bleeding & Dead on POD 5 \\
\hline 4. Edelman (1997) & 35 & 2.72 & 2.15 & 3.49 & 3.02 & Double & Off & No & Alive, 32 mo \\
\hline 5. Jackson (2001) & 53 & \multicolumn{4}{|c|}{ No data } & Single & Off & No & Alive, 90 mo \\
\hline 6. Shigemura (2009) & 63 & 1.65 & 1.49 & 2.25 & 1.84 & Double & Off & No & Alive, 16 mo \\
\hline
\end{tabular}

$P A M$, Pulmonary alveolar microlithiasis; $F V C$, forced vital capacity; $F E V_{1}$, forced expiratory volume in 1 second; $C P B$, cardiopulmonary bypass.

disease tend to have severely advanced pleural involvement characterized by dense pleural fibrosis and calcification with increased vascularity. ${ }^{4,5}$ Furthermore, if the recipient has recurrent pneumothoraces treated, a pneumonectomy to remove the native lungs will be technically more difficult. The 56-year-old patient in the report by Edelman and colleagues $^{5}$ died on the fifth postoperative day of severe and uncontrollable hemorrhage resulting from pleural involvement of the native lungs. Therefore, when treating elderly patients with end-stage PAM, the surgical team should be prepared for such difficulties that may be encountered during the operation. To avoid hemorrhagic complications, it can be emphasized that double lung transplantation should be completed without cardiopulmonary bypass. In both of the cases complicated by major bleeding, including Edelman's case, cardiopulmonary bypass was actually used, as shown in Table 1. The present patient had severe adhesions with calcification bilaterally; thus, we remained in close contact with the donor procurement team and made arrangements regarding aortic crossclamp time, which eventually helped shorten the ischemic time. In addition, to proceed without cardiopulmonary bypass, we transplanted the worst lung first followed by the other based on the findings of scintigraphy (ventilation/perfusion scan), which is of great help to identify the worst side.

In summary, we successfully performed a double lung transplantation in a case of respiratory failure resulting from end-stage PAM. The patient is the oldest reported. Although elderly recipients with end-stage PAM may have technically difficult problems related to surgery, such transplantation can be done safely and successfully when sufficient strategies are used.

\section{References}

1. Puhr L. Mikrolithiasis alveolaris pulmonum. Virchows Arch Pathol Anat Physiol Klin Med. 1933;290:156-60

2. Sosman MC, Dodd GD, Jones DW. The familial occurrence of pulmonary alveolar microlithiasis. Am J Roentgenol. 1957;77:947-1012.

3. Bonnette P, Bisson A, el Kadi NB, Colchen A, Leroy M, Fischler M, et al. Bilateral single lung transplantation. Complications and results in 14 patients. Eur J Cardiothorac Surg. 1992;6:550-4.

4. Stamatis G, Zerkowski HR, Doetsch N, Greschuchna D, Konietzko N, Reidemeister JC. Sequential bilateral lung transplantation for pulmonary alveolar microlithiasis. Ann Thorac Surg. 1993;56:972-5.

5. Edelman JD, Bavaria J, Kaiser LR, Litzky LA, Palevsky HI, Kotloff RM. Bilateral sequential lung transplantation for pulmonary alveolar microlithiasis. Chest. 1997; 112:1140-4.

6. Jackson KB, Modry DL, Halenar J, L'abbe J, Winton TL, Lien DC. Single lung transplantation for pulmonary alveolar microlithiasis. $J$ Heart Lung Transplant. 2001;20:226. 